\title{
El impacto de la unión monetaria en la gobernación del Estado
}

\author{
José María Baño León \\ Catedrático de Derecho Administrativo \\ Universidad Complutense de Madrid \\ jmbleon@jmbleon.com
}

\begin{abstract}
Resumen
La Unión Monetaria exige disciplina presupuestaria, pero al mismo tiempo, reduce drásticamente las posibilidades de una gobernación independiente. El trabajo examina el desfase entre el debate político interno en España y las posibilidades reales de una política autónoma, una vez que el Tribunal de Justicia (asunto "Pringle") ha recordado los severos límites de la solidaridad europea. Por último se analizan críticamente algunas de las reformas legislativas recientes.
\end{abstract}

Palabras clave

Unión Monetaria, democracia, unidad de mercado, solidaridad europea, reforma administrativa, decreto ley, banco central europeo.

\section{The impact of monetary union on the government of the State}

\section{Abstract}

The European Monetary Union demands a budgetary discipline. Nonetheless, at the same time, it drastically reduces the possibilities of autonomous decision making. This paper examines the mismatch between the political debate in Spain and the actual possibilities for independent policy making; particularly, once the ECJ has recalled (in the "Pringle" case), the severe obligations arising out of the European solidarity principle. The paper concludes with a critical analysis of some of the recent regulatory reforms.

\section{Keywords}

monetary Union, democracy, market unity, solidarity, administrative reform, delegated legislation, European Central Bank.

\footnotetext{
1 Proyecto de investigación del Ministerio de Economía y Competitividad DER2012-39692-C03-01.
} 


\section{LOS RETOS DE LA UNIÓN MONETARIA PARA LA POLÍTICA DE LOS ESTADOS MIEMBROS}

\section{1.- La crisis del euro y los límites de la ayuda financiera en los Estados en peligro}

La estructura de la Unión Monetaria se ha puesto a prueba como consecuencia de la gran crisis de 2008: al denunciar sus graves carencias de diseño, la crisis ha levantado acta, paradójicamente, de las consecuencias inherentes a la cesión de soberanía a la Unión Monetaria. Es el caso que, hasta 2007, los Estados de la Unión pudieron vivir de espaldas a esa cesión, y en las ocasiones en que se plantearon problemas, el Consejo Europeo cedió a las exigencias alemanas y francesas ${ }^{2}$. Pero a partir de 2008, la gravedad de la crisis ha puesto de relieve los condicionantes y requerimientos que para los países miembros tiene la cesión a la Unión de la política monetaria y la emisión de la moneda. Pueden resumirse del modo que sigue:

a) La política monetaria de la Unión, confiada al Banco Central Europeo (BCE), se fundamenta en el principio de responsabilidad autónoma de cada país miembro por su política económica, y en particular, por la política de endeudamiento.

b) El principio de prohibición de mutualización de la deuda de los países miembros es estructural y no sujeto a la apreciación discrecional del BCE. La regla del artículo 125 del Tratado de Funcionamiento de la Unión Europea (TFUE) persigue, precisamente, que sean los mercados lo que castiguen o premien la política económica de cada Estado Miembro, a través de la demanda de un mayor o menor tipo de interés por el dinero que prestan a estos Estados.

c) El miedo -o la apuesta- por una posible disolución del euro como moneda común determinó un crecimiento exponencial de los tipos de interés exigidos a aquellos países, como España, con graves problemas económicos estructurales. El rapidísimo descenso de los ingresos públicos, consecuencia de la reducción del PIB, a causa del estallido de la burbuja inmobiliaria, explica claramente las debilidades de la economía española que no son de ahora y que vienen siendo denunciadas por la mayoría de economistas desde, al menos, los años ochenta del siglo pasado ${ }^{3}$.

d) Ante estas circunstancias, la política del BCE ha consistido en procurar la máxima liquidez del sistema bancario: desde el año 2008 hasta el año 2013, el interbancario, es decir, el dinero que se presta entre los bancos, desapareció prácticamente ante los recelos y sospechas mutuas. Y, por otra parte, llevando hasta el límite sus competencias, el BCE ha autorizado compras selectivas de deuda de algunos países en dificultades y, finalmente, el 6 de septiembre de 2012 aprueba medidas conocidas como "OMTs" (Outright Monetary Transactions), consistentes en la posibilidad de que el BCE compre deuda pública en el mercado secundario, sujeta previamente a la aceptación por el Estado miembro de condiciones muy estrictas de política económica, para garantizar la estabilidad de las finanzas públicas de esos países y evitar que la compra se convirtiera en un medio de abaratar el endeudamiento de estos Estados, sin que se modificaran sus respectivas políticas económicas. Como explica la nota de prensa del BCE de 6 de septiembre de 2012, la compra de bonos está sometida a:

- Condicionalidad: condición necesaria del programa es que el país miembro se someta a un "condicionamiento estricto y efectivo", a través de un programa apropiado de ajuste macroeconómico de los mecanismos utilizados por la Facilidad Europea de Estabilidad Financiera o el Mecanismo Europeo de Estabilidad (EFSF/ESM en sus siglas en inglés), o alternativamente, a través de un programa preventivo (como el que se ha utilizado en el caso del rescate destinado al salvamento de algunas entidades financieras españolas).

- Garantía: Se considerará un instrumento para futuros casos de programas de rescate, cuando el Estado miembro tenga problemas de acceso al mercado de bonos. La compra se hará en deuda entre uno y tres años.

- Tratamiento del acreedor: El BCE acepta igual tratamiento ("pari passu”) que cualquier otro acreedor sea o no privado respecto a los bonos que compra.

- Esterilización: La liquidez que se crea a través de los “OMTs” será “esterilizada” completamente, quiere decirse que el BCE retirará esa liquidez mediante los instrumentos necesarios que no se especifican.

Como se ve en el comunicado de prensa, el BCE pone por delante del programa de compra de deuda el condicionamiento de la política económica de los Estados que pidan ayuda. En el informe presentado al Tribunal

2 Muy representativa la STJUE de 13 de Julio de 2004 que anula las conclusiones del Consejo, de 25 de noviembre de 2003 , que suspendía el procedimiento de déficit excesivo y modificaba las recomendaciones anteriormente adoptadas por el mismo Consejo, respecto de Alemania y Francia. Cfr. Álvarez Martínez, J.; Salinas Alcega, S.: “La aplicación del procedimiento de déficit excesivo: los casos de Francia y Alemania. Análisis de la Sentencia del Tribunal de Justicia de las Comunidades Europeas de 13 de julio de 2004 (asunto C27/04, Comisión contra Consejo)", Presupuesto y Gasto Público 40/2005, pág. 9-28.

3 Cfr. Pérez García, F. (dir): Crecimiento y competitividad Trayectoria y Perspectivas de la Economía Española. Fundación BBV/IVIE, Bilbao 2011. 
Constitucional Federal Alemán, (TCFA), en el marco del recurso de amparo interpuesto contra el citado acuerdo del BCE, el alto organismo europeo sostiene lo siguiente: las “OMTs" están cubiertos por su mandato, en la medida en que "los miedos infundados de los inversores respecto de la reversibilidad del euro hubieran conducido a un encarecimiento injustificado de los tipos de interés" (punto 2 de los antecedentes del Auto del TCFA de 14-01-2014, BVerfG, 2BvR 2728/13), que impide los mecanismos de transmisión de la política monetaria. Recuerda, por último, el BCE que el artículo 18.1 del Protocolo sobre los Estatutos del Sistema Europeo de Bancos Centrales le autoriza a “operar en los mercados financieros comprando y vendiendo directamente (al contado y a plazo), o con arreglo a pactos de recompra, prestando o tomando prestado valores y otros instrumentos negociables, ya sea en monedas comunitarias o en divisas extracomunitarias, así como en metales preciosos".

\section{2.- La Sentencia "Pringle": Las reformas de política económica son condición previa para que la ayuda financiera sea conforme al Derecho de la Unión}

Luego volveremos sobre este procedimiento judicial que ha dado lugar, por vez primera, a que el TCFA plantee una cuestión prejudicial ante el Tribunal de Justicia sobre la validez de los "OMTs". Importa ahora observar que la estabilidad presupuestaria y el saneamiento de las finanzas públicas, como condición "sine qua non" de cualquier ayuda financiera a los Estados miembros, ha sido enérgicamente subrayada por el Tribunal de Justicia en la Sentencia Pringle, de 27 de noviembre de 2012 (C-370/12). La cuestión prejudicial, planteada por la "Supreme Court" irlandesa, tiene por objeto la validez de la Decisión 2011/199/UE Consejo Europeo, de 25 de marzo de 2011, que modifica el artículo 136 del TFUE en relación con el mecanismo de estabilidad (EFSF) para los países cuya moneda es el euro, así como la interpretación de diversos artículos del Tratado de la Unión Europea (TUE) y del TFUE.

En dicha sentencia, adoptada por el Pleno del Tribunal de Justicia, se hacen pronunciamientos de extrema importancia sobre los Tratados y sobre los límites de la solidaridad en la Unión Europea. Es curioso que la Sentencia haya tenido escasísimo eco en la opinión pública, y aún en la doctrina, pese a la relevancia de las consideraciones jurídicas ofrecidas por el Tribunal.

La "Supreme Court" tenía dudas sobre si la nueva redacción del artículo 136.3 TFUE, que prevé el establecimiento de un mecanismo de estabilidad, podía adoptarse por el procedimiento simplificado, al afectar a la competencia de la Unión prevista en la primera parte del Tratado relativa a la política monetaria de la Unión y a la coordinación de las políticas económicas de los Estados miembros, y consecuentemente debía haber sido adoptada por el procedimiento ordinario de revisión del Tratado previsto en el artículo 48 TUE.

Es obvio que la modificación afecta a las políticas monetarias de los países que solicitan ayuda en el marco del mecanismo de estabilidad. Por eso, la Sentencia dice que el TFUE al limitarse a reconocer medidas de coordinación, no confiere "una competencia específica a la Unión para establecer un mecanismo de estabilidad como el previsto en esa Decisión” razón por la cual el artículo 136.3 no afecta a las competencias de la Unión. Los Estados miembros, cuya moneda es el euro, pueden establecer por vía convencional un tratado para organizar un mecanismo de estabilidad.

Pero quedaba por despejar una segunda incógnita, la más interesante a nuestros efectos: si ese mecanismo de estabilidad afectaba al Derecho de la Unión, en particular a la prohibición general de solidaridad financiera (artículo 125 TFUE en relación con las competencias de coordinación de la política económica). Y a esta cuestión responde claramente el Tribunal: la modificación respeta el Derecho de la Unión.

"Pues bien, las estrictas condiciones a que se supedita la concesión de una asistencia financiera por el mecanismo de estabilidad en virtud del apartado 3 del artículo 136 TFUE, que en la disposición objeto de la revisión del Tratado FUE, tratan de garantizar que ese mecanismo, respeta en su funcionamiento el Derecho de la Unión; incluidas las medidas adoptadas por la Unión en el marco de la coordinación de las políticas económicas de los Estados Miembros".

Este criterio de subordinación de cualquier ayuda financiera a la obligación de introducir medidas de política económica se reitera, aún con más énfasis, cuando el Tribunal interpreta el artículo 125, frente a la cuestión prejudicial planteada por el Tribunal irlandés: ¿un acuerdo como el Tratado MEDE vulnera la cláusula de "no corresponsabilidad financiera" enunciada en el artículo 125 TFUE?

Para contestar a esta pregunta el Tribunal distingue entre la prohibición de ayuda al BCE (artículo 123 TFUE) y la prohibición a los estados miembros (artículo 125 TFUE). El Tribunal considera que el artículo 125 no prohíbe a los estados miembros todo tipo de ayudas, sino sólo aquellas que pueden “debilitar” la obligación de los estados 
miembros de observar una política presupuestaria sana. Es pertinente reproducir los cinco párrafos decisivos de esta Sentencia:

“Así pues, para determinar las formas de asistencia financiera que son compatibles con el artículo 125 TFUE, se ha de atender al objetivo perseguido por ese artículo.

Debe recordarse a ese efecto que la prohibición prevista en el artículo 125 TFUE tiene su origen en el artículo 104 B del Tratado CE (que pasó a ser el artículo 103 CE), el cual fue insertado en el Tratado CE por el Tratado de Maastricht.

Ahora bien, de los trabajos de elaboración de ese último Tratado se deduce que el artículo 125 TFUE trata de asegurar que los Estados miembros observan una política presupuestaria sana (véase el proyecto de tratado por el que se revisa el Tratado constitutivo de la Comunidad Económica Europea a fin de instaurar una unión económica y monetaria, Boletín de las Comunidades Europeas, Suplemento 2/91, pp. 22 y 52). En efecto, la prohibición enunciada en el artículo 125 TFUE garantiza que, cuando contraigan deudas, los Estados miembros permanezcan sujetos a la lógica del mercado, la cual debe incitarles a mantener una disciplina presupuestaria. El respeto de esa disciplina contribuye a escala de la Unión a la realización de un objetivo superior, a saber, el mantenimiento de la estabilidad financiera de la unión monetaria.

Atendiendo a ese objetivo perseguido por el artículo 125 TFUE, es preciso estimar que esa disposición prohíbe a la Unión y a los Estados miembros la concesión de una asistencia financiera cuyo efecto fuera debilitar la incitación del Estado miembro beneficiario de esa asistencia a seguir una política presupuestaria sana. Como resulta del punto 5 del dictamen del BCE sobre un proyecto de decisión del Consejo Europeo que modifica el artículo 136 del Tratado de Funcionamiento de la Unión Europea en relación con un mecanismo de estabilidad para los Estados miembros cuya moneda es el euro, la activación de una ayuda financiera en virtud de un mecanismo de estabilidad como el MEDE sólo es compatible con el artículo 125 TFUE si es indispensable para la salvaguardia de la estabilidad financiera de la zona del euro en su conjunto y se supedita a condiciones estrictas.

En cambio, el artículo 125 TFUE no prohíbe la concesión de una asistencia financiera por uno o varios Estados miembros a un Estado miembro que siga siendo responsable de sus propios compromisos frente a sus acreedores, siempre que las condiciones asociadas a esa asistencia sean apropiadas para incitar a este último a poner en práctica una política presupuestaria sana."

Queda, pues, muy claro en el razonamiento del Tribunal que el mecanismo del MEDE no deroga ni contraviene la prohibición del mutualización de la deuda de los países miembros de la Unión. Al contrario, el Tribunal, como no podía ser de otra manera ${ }^{4}$, atendidos los estrictos términos de los artículos 123 a 126 TFUE, subraya que el objetivo final de la Unión es una política presupuestaria sana, lo que quiere decir en otros términos, que cualquier ayuda financiera debe tener como finalidad esa estabilidad presupuestaria, condicionando hasta donde sea necesario la política económica del Estado afectado. Los Estados en dificultades sólo conservan frente a esta ayuda condicionada, la alternativa (si es que del tal puede hablarse) de suspender el pago de la deuda, es decir, de quebrar, pero ya no conservan ninguna otra posibilidad de política monetaria al haberla cedido a la Unión, salvo naturalmente que la bancarrota del país vaya acompañada de la salida del euro; una alternativa soberana que hasta el momento ninguno de los países miembros ha manejado seriamente, acaso porque nadie sabe muy bien cuáles serían las consecuencias para la propia idea de Unión Europea.

\section{3.- La reacción del Tribunal Constitucional Alemán frente a la política del BCE: la cuestión prejudicial de 14 de Enero de 2014.y la Sentencia de 18 de marzo de 2014}

La doctrina del TJUE no puede ser más diáfana. No obstante, el TCFA, a la primera oportunidad que ha tenido, ha decidido plantear por vez primera en su historia, una cuestión prejudicial sobre la validez del mecanismo preventivo de compra de deuda anunciado por el Presidente del BCE en Agosto de 2012, e instrumentado en el acuerdo de 6 de septiembre de 2012, al que más arriba hemos hecho referencia. El caso es ciertamente representativo

4 Sobre la prohibición de perecuación financiera como idea estructural de la Unión Monetaria, me remito ahora a mi trabajo “Libre competencia y regulación económica en un mundo en crisis (una visión contemporánea de la soberanía en la Unión monetaria)”, en Asociación de Letrados del Tribunal Constitucional, La Constitución Económica, C.E.P.C, Madrid 2012, págs. 239 y ss. 
de las tensiones políticas existentes en el país más poderoso económicamente de la Unión, polémica a la que ha dado alas jurídicas el TCFA, admitiendo desde la Sentencia Maastricht de 19935, recursos de amparo basados en un derecho fundamental creado por el propio Tribunal alemán, como derivación del artículo 38 de la Ley Fundamental de Bonn, que se limita a decir que los diputados del Bundestag son elegidos por los ciudadanos mediante voto general, directo, igual, libre y secreto ${ }^{6}$.

Pues bien, interpuesto recurso de amparo ante el TCFA frente al acuerdo del BCE de 6 de septiembre de 2012, y a la inactividad del Gobierno Federal alemán, consistente en no haber planteado demanda ante el TJUE contra dicho acuerdo sobre OMTs y contra la compra de deuda pública, el TCFA decide suspender el procedimiento y presentar cuestión prejudicial al Tribunal de Justicia, sobre si el mencionado acuerdo del BCE es incompatible con los artículos 119 y 127, apartados 1 y 2, TFUE, y con los artículos 17 a 24 del Protocolo sobre la constitución del Sistema Europeo de Bancos Centrales y del Banco Central Europeo, porque podría exceder del mandato del BCE sobre política monetaria e invadir las competencias de los Estados miembros?.

El planteamiento de esta cuestión prejudicial supone un espaldarazo a la preeminencia del TJUE en la interpretación de los Tratados, más allá de las múltiples reservas que la jurisprudencia del Tribunal Constitucional Alemán había venido manteniendo desde las Sentencias "Solange" primero, y luego desde la Sentencia Maastricht. Y parece claro que el Tribunal Constitucional alemán no ha sido indiferente a la Sentencia "Pringle" que claramente, como hemos expuesto, ha puesto límites muy precisos a las ayudas financieras. De hecho en el parágrafo 100 del Auto, el TCFA se permite hacer una interpretación conforme de las medidas no convencionales del BCE desde el punto de vista del Derecho de la Unión:

“El acuerdo sobre OMTs sería desde el punto de vista del Bundesverfassungsgericht no impugnable, si se interpretara a la luz de los artículos 119 y 127 y siguientes del TFUE así como del artículo 17 y siguientes del Protocolo sobre el sistema europeo de Bancos Centrales, o se limitara su aplicabilidad, de modo que no socave la condicionalidad del Programa de Ayuda del mecanismo europeo de facilidad financiera y el mecanismo de estabilidad y tenga un carácter meramente de apoyo a la política económica en la Unión. El artículo 123 TFUE presupone que el recorte de la deuda está prohibido, los bonos de los países miembros no pueden ser comprados en cuantía ilimitada, y la influencia en la formación de los precios en el mercado tiene que evitarla en lo posible. Las declaraciones del representante del Banco Central Europeo es el procedimiento jurídico-constitucional sobre el marco de condiciones para la ejecución del acuerdo OMT (volumen limitado de una posible compra de deuda pública; ninguna participación en amortización de deuda; mantenimiento de un espacio temporal ente la emisión de la deuda y su compra; no mantenimiento de la deuda hasta vencimiento) indican que una tal interpretación conforme del Derecho de la Unión sería compatible con el sentido y la finalidad del acuerdo OMT".

Resulta obvio, más allá de las importantes aclaraciones que sobre el programa sostuvo el representante del BCE, que el Tribunal alemán acepta implícitamente el mecanismo de la OMT y que la cuestión prejudicial pretende reforzar jurídicamente los límites a la competencia del Banco Central Europeo.

Este planteamiento contrasta con la posición del Banco Central alemán, Bundesbank, cuya postura en el proceso de amparo ante el TCFA dista radicalmente de la del BCE. Para el Bundesbank, "la tesis del BCE sobre la necesidad de restaurar el mecanismo de transmisión monetaria es dudosa y no justifica el acuerdo sobre “OMTs". No puede distinguirse -añade el Bundesbank- entre incrementos justificados e injustificados de la deuda pública. En el caso de las "OMTs" no se trata de dar eficacia a la política monetaria, lo demuestra la circunstancia de que una afectación al mecanismo de trasmisión de la política monetaria debe admitirse, si un Estado miembro no mantiene sus obligaciones derivados de lo negociado con la Facilidad Europea de Estabilidad Financiera o con el Mecanismo

5 BVerfGE, 89, 155, 171 ss.: "El artículo 38 GG excluye, en el ámbito de aplicación del artículo 23 GG (transferencia de competencias a la Unión Europea), que la legitimación de los poderes estatales y la capacidad de influencia en su ejercicio, derivada de la elección, sea vaciada mediante el desplazamiento de competencias y funciones del Bundestag, de manera tal que se vulnere el principio democrático, declarado inviolable conforme al artículo 79, apartado 3 en relación con el artículo 20, apartados 1 y 2 GG".

6 Vid. Sentencias del TCFA Lisboa, de 30 de junio de 2009; Ayuda a Grecia, de 7 de septiembre de 2011; Resolución denegando medidas cautelares, de 12 de septiembre de 2012.

7 La resolución del TCFA cuenta con dos votos particulares. Entienden los magistrados discrepantes que el amparo debió ser inadmitido: a) en cuanto su objeto -la inactividad del ejecutivo y legislativo federales-, excede de los límites de la división de poderes y el principio democrático (opinión de la magistrada Lübbe-Wolf); b) porque la Constitución no ha otorgado al Tribunal Constitucional un poder de supervisión general de la Constitución. La Constitución no reconoce al ciudadano una acción para exigir, por vía judicial, que el poder legislativo y ejecutivo impugnen determinados actos de las instituciones europeas. La Constitución reconoce al poder ejecutivo y legislativo una amplia capacidad para valorar si recurren o no las decisiones europeas, partiendo de la base de que la Unión Europea es una Comunidad de Derecho (Opinión del juez Gerhardt). 
de Estabilidad Europea". También critica el Bundesbank los peligros de la compra de deuda, pues puede afectar a la formación de precios de la deuda en el mercado: los operadores en el mercado podrían confiar en que el eurosistema compraría finalmente sus títulos y, en consecuencia, podría aumentar el traslado de deuda de los Estados al eurosistema. Finalmente el Bundesbank dice que cualquier pérdida del Banco Central alemán está unida a una afectación al presupuesto, pues económicamente el riesgo de compra de bonos soberanos por el eurosistema no se distingue del mecanismo de estabilidad, con la diferencia de que no existe ningún control parlamentario (alemán) en el primero caso y sí en el segundo.

Esta muy marcada diferencia de criterio entre el Banco Central Europeo y el Banco Central Alemán es muy significativa, no sólo porque refleja una valoración radicalmente diferente de la competencia del BCE para acometer la compra de deuda de los países del euro en dificultades. El regulador bancario alemán forma parte del sistema europeo de bancos centrales, de modo que la postura que se ha impuesto en el BCE no es precisamente la más liberal desde el punto de vista económico. Y esta diferencia de criterios, sin duda, explica también que el Tribunal Constitucional alemán haya planteado una cuestión prejudicial, cuyo significado, en mi opinión, supone aceptar por adelantado el criterio de la doctrina "Pringle", es decir: la ayuda financiera es admisible siempre que sea limitada y controlada mediante la imposición de condiciones garantes de una política presupuestaria rigurosa.

Corrobora este criterio la STCFA de 18 de Marzo de 2014 (BVerfG, 2BvR 1390/12), que desestima diversos recursos contra la ratificación alemana del Tratado sobre creación de un mecanismo de estabilidad (MEDE), sobre la reforma del artículo 136 del TFUE, sobre el Tratado de 2 de Marzo de 2012 de Estabilidad, Coordinación y gobierno en la Unión Económica y Monetaria, y contra la inactividad del gobierno federal sobre los saldos TARGET 2 y sobre los cambios en el marco del Sistema Europeo de Bancos Centrales. El extremo más controvertido en el procedimiento era si el Tratado MEDE podía interpretarse de tal forma que la obligación de contribución de los Estados al Fondo fuera ilimitada. Para el Tribunal, la Declaración interpretativa de los Estados parte, de 2 de febrero de 2012, (BOE 6-10-2012) y la Declaración unilateral alemana del mismo día, "excluyen el peligro de una tal interpretación". Los Estados parte del Tratado MEDE declaran que el artículo 8, apartado 5, del Tratado "limita todas las responsabilidades de pago de los miembros del MEDE en virtud del Tratado en el sentido de que ninguna disposición del Tratado puede ser interpretada como conducente a obligaciones de pagos superiores a la parte del capital autorizado correspondiente a cada miembro del MEDE (...), sin el acuerdo previo del representante de cada miembro y respetando los procedimientos nacionales" ${ }^{\prime \prime}$. Con esta jerga casi indescifrable, Alemania se ha asegurado que cualquier ayuda futura, por encima de su aportación al capital con que actualmente está dotado el MEDE, requiera el acuerdo del Parlamento Federal.

\section{CONSECUENCIAS ECONÓMICAS DE LA ACTUACION DEL BCE}

Es un lugar común, entre los observadores económicos, afirmar que el anuncio del programa "OMT" ha sido decisivo en el cambio de rumbo experimentado por el tipo de interés exigido por los mercados a la deuda pública de los Estados miembros más expuestos a la crisis económica. Este tópico responde fielmente a lo sucedido si se tiene en cuenta las estadísticas disponibles.

De Julio de 2012 (el 26 de Julio anunció el Presidente del BCE que el Banco adoptaría todas las medidas necesarias para mantener el euro) a Julio de 2013, todos los países expuestos a la tormenta financiera vieron rebajados sensiblemente los diferenciales de deuda con el bono alemán a diez años. Y en este momento (marzo de 2014) todavía se han estrechado más las diferencias.

Si en el año 2012 los inversores llegaron a exigir un 4,01\% de rentabilidad superior al bono alemán (401 puntos básicos) en febrero y marzo de 2014 se situaba el diferencial entre el 1,94\% de febrero y el 1,87\% del periodo transcurrido en el mes de marzo. Una evolución de más de 200 puntos básicos en poco más de un año y medio es suficientemente significativa de la buena acogida que ha tenido un programa, el de la OMT, que hasta el momento no se ha puesto en marcha. Esta reducción de diferenciales todavía es mayor en otros países, por ejemplo Portugal.

Millaruelo y Del Río 9 han mostrado que, frente a lo que a veces se piense, las llamadas medidas no convencionales del BCE, de las que el programa de OMT es el último ejemplo, han contribuido decisivamente a estabilizar los mercados, y con ello a aliviar las tensiones financieras. Por otra parte, es indiscutible que los programas de ayuda financiera solo han sido posibles cuando los Estados afectados han aceptado dolorosas políticas de contención

8 Esta declaración, forzada por Alemania, es una consecuencia directa de la STCFA de 7 de septiembre de 2011 (BVerfGE, 2 BvR 967/10), Ayuda a Grecia, en la que el Tribunal dijo: La Ley alemana de ayuda a Grecia y el instrumento de la Facilidad Financiera (EFSF) sólo son admisibles si establecen el contenido, finalidad y límite máximo de la ayuda, de modo que el Parlamento Federal tenga siempre la competencia efectiva para aprobar las ayudas financieras futuras.

9 “Las medidas de política monetaria no convencionales del BCE a lo largo de la crisis”. Boletín Económico del Banco de España, Enero 2013, págs. 89-99. 
del gasto. En unos casos, con ayuda financiera global (Irlanda, Grecia o Portugal), y en otros, con ayudas parciales. Ese es el caso de la línea de crédito de cien mil millones de euros abierta a España, en Julio de 2012, para poder acometer el salvamento de las entidades financieras en dificultades, de la que España ha dispuesto de más de cuarenta mil millones.

El indudable efecto positivo de estos planes no oculta la realidad de los defectos estructurales de la Unión monetaria. Hay un acuerdo general en que se ha conseguido ganar tiempo ${ }^{10}$, pero que el problema de fondo institucional de la Unión monetaria es que no es posible un gobierno adecuado de la Unión si los países miembros no ceden parcelas adicionales de soberanía. De las reformas en marcha, las más avanzadas son el refuerzo de los mecanismos de coordinación de la política económica (rectius: control de los presupuestos nacionales) ${ }^{11}$ y la supervisión bancaria, que se encomienda al Banco Central Europeo; en una fase mucho más inmadura están la unión fiscal, y la más peliaguda, la reforma institucional, para que haya una mayor conexión entre los parlamentos nacionales, el Parlamento europeo y la Comisión europea, es decir, un incremento de la legitimación democrática de las instituciones europeas.

\section{CONSECUENCIAS JURÍDICO-PÚBLICAS EN EL CASO DE ESPAÑA}

A tenor de cuanto se ha dicho ya, pocas dudas caben de que en el medio plazo nuestro país se debería ver abocado a mantener y profundizar en políticas de saneamiento estructural de nuestra economía, lo que exigiría un acuerdo básico de las fuerzas políticas. Podría resumirse la situación del modo siguiente: si se camina hacia un incremento del control europeo de las políticas presupuestarias de los países miembros, porque es la única vía para mantener la Unión monetaria a largo plazo, el grado de independencia efectiva de las políticas de Estados como España se reduce drásticamente. En consecuencia el eje de la política interna debería girar sobre las reformas necesarias para ejecutar de la mejor manera posible, es decir, con el menor coste social, unas políticas que inexorablemente nos vienen impuestas.

Sin embargo, es un hecho que el debate político-electoral sigue girando sobre el mito de una soberanía estatal que permitiría políticas muy diferentes. Los regalos electorales siguen siendo la base de unas promesas que nada tienen que ver con la dura realidad. La clase política ha intuido rápidamente que plantear el debate en términos realistas contribuiría a su deslegitimación, pues al fin y al cabo, si los contribuyentes pagan para que los políticos decidan los grandes asuntos, ¿por qué habrían de seguir haciéndolo si en realidad las grandes decisiones se adoptan mucho más allá de nuestras fronteras?

Desde luego esta no es cuestión que atañe a España exclusivamente, ni siquiera sólo a los países en dificultades. En todos los Estados de la Unión se plantea el mismo problema de falta de legitimación democrática de las instituciones europeas. Las elecciones, ya sean europeas o locales, se resuelven por factores exclusivamente de política interna. Pero en el caso de países "eurodébiles", como es España, la distancia entre la realidad en la toma de decisiones y el debate político es mucho más grave, porque nuestras posibilidades de influencia en las instituciones europeas son proporcionales, no sólo a nuestro tamaño, sino también al grado de saneamiento de las finanzas públicas.

El hecho de que se haya considerado que un programa de ayuda financiera global afectaba a nuestra soberanía, y que había que evitarlo a toda costa, no obedece a ninguna lógica económica. Al fin y al cabo, si una reforma en profundidad de nuestras cuentas públicas se considerara como un bien en sí mismo, el programa de rescate no sería intrínsecamente malo, sino todo lo contrario. Lo que en realidad ha marcado la resistencia al rescate es el temor a la pérdida de influencia y de poder de la clase política dirigente: si se suprime el mito de la soberanía, la deslegitimación de los representantes políticos todavía será mucho intensa. Una muy buena razón para evitar en todo lo posible dar la impresión de que el margen de acción de los gobernantes es mucho más reducido de lo que el debate político permite suponer ${ }^{12}$. Es el mismo mito que alienta los planteamientos de independencia en Escocia o Cataluña, pues ambas viven en el fondo de una aspiración, la soberanía, que entendida al modo de Bodino, hace años que no está disponible, tampoco para los Estados de los que pretenden segregarse. No es un proceso

10 Además de la bibliografía económica citada, cfr. significativamente, Callis, Chr: "Die Reform der Wirtschafts - und Wahrungsunion als Herausforderung für die Integrationasarchitektur der Eu”. DÖV. 20 (2013), pág. 785 y ss.

11 Sobre el llamado six-pack que acompaña al Pacto de Estabilidad y Crecimiento, vid. Menéndez, A. J.: De la crisis económica a la crisis constitucional europea, Eolas Ediciones, León 2012, págs. 79 y ss.

12 Cuando es necesario el cumplimiento del objetivo de déficit público marcado por la Unión Europea -y constitucionalmente obligatorio en España- las opciones de política económica se reducen en grado sumo: evidentemente hay una pluralidad de combinaciones entre el aumento de los ingresos y la reducción de gastos. Pero el objetivo de reducción de déficit es irrenunciable jurídicamente. El ejemplo de Portugal lo demuestra sin asomo de duda: el Tribunal Constitucional portugués ha declarado inconstitucionales medidas tales como el recorte de la paga extra de los funcionarios, las pensiones de los funcionarios, o las pensiones de invalidez., en general por ir en contra del principio de igualdad. Sin embargo, ello no ha supuesto un cambio de política económica, sino nuevos aumentos de impuestos o recortes en otros gastos, para respetar la igualdad en los sacrificios, y sobre todo los compromisos con el Fondo Europeo de Estabilidad Financiera (FEEF). 
de segregación para ser independientes: los nacionalistas escoceses o catalanes no quieren separarse de la Unión Europea, lo que quieren es un proceso de independencia para ser dependientes en condiciones de igualdad formal; a lo que aspiran es a ser pequeños Estados dentro de la Unión Europea bajo el paraguas económico del euro.

Esta misma razón de fondo (la auto-protección de las élites políticas, y con ellas, las de los grupos económicos con más capacidad de influencia) explica el "porqué" del temor a las reformas de fondo de un sistema, en el que es advertible un amplio grado de desafección popular. Y es que tales reformas no sólo incidirían directamente en el estatuto de la clase política dirigente; incrementarían, también, la deslegitimación democrática de nuestros representantes, puesto que cualquier reforma de calado podría percibirse como una imposición europea.

En los análisis económicos sobre la situación en la Unión monetaria va ganando cuerpo la idea de que el problema económico fundamental que tiene la Unión es jurídico, o político-institucional, en la jerga más al uso. Véase, por ejemplo, lo que opina el director general del servicio de estudios del Banco de España tras analizar la política del BCE para arrostrar la crisis del euro:

"En todo caso, la solución duradera de los problemas emergidos depende en gran medida de la acción en el tercero de los frentes, que es el que corresponde a las medidas que han de tomar las autoridades europeas para reformar y fortalecer la gobernanza del euro y facilitar el camino desde una unión exclusivamente monetaria hacia una unión económica más genuina, según la hoja de ruta aprobada por el Consejo Europeo, que comprende una unión bancaria, una unión económica, una unión fiscal y un reforzamiento de la legitimidad democrática de todo el procedo, que puede entenderse como una suerte de unión política"’3.

Otro ejemplo ilustrativo proveniente del mismo servicio de estudios del Banco de España:

“Con todo, conviene recordar que las actuaciones de política monetaria, ya sean convencionales o no convencionales, no permiten resolver las causas últimas que han generado la desconfianza de los inversores y las tensiones en los mercados soberanos y bancarios. Su papel continúa, sin embargo, siendo fundamental para ganar el tiempo necesario para la adopción de las medidas encaminadas a la consolidación de las finanzas públicas, al saneamiento y reestructuración del sector bancario y al refuerzo del marco institucional de gobernanza del área que permitan asegurar la viabilidad a largo plazo del proyecto de integración europeo" ${ }^{14}$.

Parece claro, no obstante, que el retorno de los inversores no será suficiente a medio plazo para restaurar las condiciones que hagan posible la continuidad del proyecto de integración europeo, si no se restablece la confianza de los ciudadanos. El grado de soberanía efectiva de los Estados “eurodébiles” y la viabilidad de la Unión Monetaria dependen mucho más de la credibilidad de los mercados que de factores internos. Esto significa que cualquier crisis de confianza de los inversores puede alterar sustancialmente ese margen de soberanía. El ejemplo de España es elocuente ${ }^{15}$ : con un endeudamiento del 93,90\% del PIB en diciembre de 2013 (en 2007 era tan sólo del 36,3\%), cualquier subida del interés exigido a la deuda produce un efecto restrictivo sobre el gasto público ${ }^{16}$. Al $\mathrm{Contrario}$ el aumento de la confianza de los inversores y la disminución de los tipos de interés permite cierto desahogo en el gasto. Como el gobierno responde frente a los electores, la tentación de ocultar la realidad y no afrontar medidas estructurales es enorme.

En este contexto, el factor jurídico, que la preeminencia del análisis económico había relegado al simple papel de comparsa normativo de las decisiones pretendidamente técnico-científicas, emerge como un factor decisivo, que los juristas, en particular los iuspublicistas, deben vindicar sin complejos, tanto en el plano del Derecho de la Unión como en el ámbito estrictamente interno de los países miembros. A esta última perspectiva, en lo que concierne a España, se dedicarán las páginas siguientes.

13 Malo de Molina, J. L.: “La respuesta del Banco Central Europeo a la crisis”, Boletín Económico del Banco de España, Julio-Agosto de 2013, pág. 123. Los subrayados son nuestros.

14 Millaruelo, Antonio/ Del Rio, Ana, Op. cit., pág. 99. Los subrayados son nuestros.

15 Fuente: Banco de España: "Deuda según el protocolo de Déficit. Excesivo y activos financieros frente a Administraciones Públicas"

16 Gordo, L., Hernández de Cos, P., Pérez, J. J.: “la evolución de la deuda pública en España desde el inicio de la crisis”, Boletín Económico del Banco de España, Julio-Agosto 2013, págs. 77-95, dicen que la actualización del Programa de Estabilidad prevé “estabilizar la deuda en 2016 en el entorno del 100\% del PIB, para comenzar a reducirse con posterioridad. La consecución de estos objetivos presupuestarios requiere un esfuerzo de magnitud considerable, pero su cumplimiento es primordial para afianzar la credibilidad en el proceso de consolidación y reconducir la senda del endeudamiento hacia niveles más moderados". 


\section{REFORMAS EJECUTADAS Y REFORMAS PENDIENTES}

La modificación del artículo 135 de la Constitución por el procedimiento de urgencia para implantar el principio de estabilidad presupuestaria es como el alfa y omega que resume la línea emprendida por los Gobiernos Zapatero y Rajoy. Alfa, porque realmente ancla en la Constitución la estabilidad de las cuentas públicas como valor constitucional predominante; omega, porque hasta el momento se ha rehuido (salvo la reforma laboral) atacar a fondo los problemas estructurales jurídicos y económicos para centrarse en todas aquellas medidas que minimicen el déficit público.

Las reformas puntuales del régimen de pensiones, de la seguridad social, del desempleo, las medidas de ahorro sanitario, las restricciones temporales en las remuneraciones de los funcionarios públicos, los incrementos, también "temporales", en los impuestos directos, y permanentes en los indirectos, tiene el tono y la medida de una legislación de emergencia encaminada a controlar el gasto público. Es imposible no establecer un paralelismo con la otra gran crisis, la de 1929 y las medidas de urgencia adoptadas en Alemania durante el gabinete Brünning.

La Ley Orgánica 2/2012, de abril, de Estabilidad Presupuestaria y Sostenibilidad Financiera, al consagrar esos dos principios, establece un marco de intervención de las políticas públicas que no puede separarse de esos objetivos ideales. En el marco de la Administración Local, la Ley 27/2013, también alude a la sostenibilidad (financiera, se entiende) de la Administración Local, entendiendo que no basta con la Ley Orgánica general y que se requiere "adaptar algunos aspectos de la organización y funcionamiento de la Administración Local así como mejorar su control económico-financiero". Es como si el ímpetu de las reformas se acomodara mejor a lo que en cada caso marca el límite del déficit presupuestario renunciando de momento a reformas más profundas, o, en el caso de las entidades locales, que se utilizara el "slogan" de la sostenibilidad como excusa para reducir el ámbito de autonomía de las Corporaciones Locales, lo cual no es bueno o malo en sí mismo, pero parece querer justificarse en un aparente criterio objetivo (la sostenibilidad y la racionalización) en vez de explicarse como una opción política del legislador básico estatal.

Esta línea de reformas y la forma de plantearlas elude arrostrar otros graves problemas estructurales cuya resolución ayudaría en mucho a aquellos objetivos de estabilidad y sostenibilidad. No puede negarse ni la importancia ni el cambio de mentalidad profundo que implica la Ley 2/2012 y la Ley Orgánica 9/2013, de control de la deuda comercial en el sector privado, que modifica aquélla. Lo que queremos subrayar es que no es suficiente, en la medida en que elude algunos de los problemas estructurales de la Administración en España.

Vaya por delante que las reformas acometidas desde la perspectiva de la estabilidad presupuestaria no son baladíes, ni puede restárseles importancia. Únicamente criticamos que tienen una perspectiva muy estrecha, son medidas extraordinarias frente a una situación de emergencia de las cuentas públicas. Lo que nos preguntamos es si esas medidas necesarias son suficientes a medio plazo. Ya hemos visto que los requerimientos europeos no son coyunturales y que hay un peaje por ser miembro de la Unión Monetaria, que requiere la adopción de reformas más profundas.

A nuestro juicio, estas medidas exigirían un amplio acuerdo de las fuerzas políticas, incluso su ejecución mediante un gran gobierno de coalición, en la medida en que ésta es la única forma de exponer ante la opinión pública cuál es la realidad de la Unión Monetaria y las condiciones estructurales que impone. De lo contrario, sin esa gran coalición, nos encontramos con una amplia brecha entre el debate político-jurídico interno y la realidad impuesta por la Unión Monetaria. Como el debate se sitúa en la política interna, la oposición siempre va a exigir al gobierno de turno un cambio de política, que éste no tiene posibilidades de hacer en el marco de la Unión Monetaria. Sin posibilidad de intervención sobre la masa monetaria ni de devaluación, las dos armas de la política monetaria española desde el plan de estabilización de 1959, el margen de actuación de cualquier gobierno se estrecha. Basta comparar dos momentos críticos de la España contemporánea con nuestra situación actual. 1959, con el aludido Plan de Estabilización, que dio fin al aciago período de la autarquía e inició la modernización de la economía; 1977, con los Pactos de la Moncloa, que pusieron las bases para superar una economía excesivamente intervenida, que la crisis del petróleo de 1973 y el agotamiento político del franquismo había dejado inerme. En ambas crisis la política monetaria acompañó la política de liberalización de la economía. Y, de hecho, desde 1959 hasta la actualidad, la retirada progresiva del Estado respecto de las relaciones laborales o de la economía no ha hecho sino incrementarse. La gran diferencia con la situación actual es que ahora España no dispone de política monetaria. La inexistencia de este poder en manos del Estado no permite aliviar o endulzar el proceso de liberalización, que implica -velis nolis- suprimir o reducir el empleo subvencionado y limitar las prestaciones sociales. La inflación y la devaluación permiten enmascarar las crisis y ganar en competitividad. Pero al suprimirse ese remedio, las políticas de contención del gasto tienen un impacto muy negativo sobre la opinión pública y unos costes sociales muy elevados.

Por otra parte, la inexistencia de los recursos de la política monetaria influye en la adopción de cualquier me- 
dida de reforma. Es muy ilustrativo el reciente Informe de la Comisión de Expertos para la reforma fiscal presidida por el profesor Lagares: todo el esfuerzo argumentativo de la Comisión tiene como eje la necesidad de que la nueva fiscalidad se oriente hacia una reducción de los costes e incentivación del trabajo y de la actividad económica, con el objetivo de aumentar la competitividad (incremento de la imposición indirecta, reducción de la contribución empresarial a la financiación de la Seguridad Social, reducción de la imposición directa). No en balde el Gobierno se comprometió con la Comisión Europea a introducir "un sistema tributario acorde con los esfuerzos de consolidación fiscal y más propicio para el crecimiento"; y también a reducir "el riesgo inducido por la fiscalidad a favor del endeudamiento o la propiedad de la vivienda"17.

Sin embargo, las críticas en la opinión pública no se han hecho esperar e incluso el Gobierno mismo ha anunciado que la reforma no incorporará todas las medidas. La crítica se ha hecho tanto desde posiciones conservadoras, que reclaman una reducción de impuestos (obviando el objetivo -irrenunciable jurídicamente- de reducción del déficit), como desde posiciones de izquierda, que critican la reducción de la contribución directa. Significativo es que haya un acuerdo generalizado en contra del incremento de la fiscalidad a un recurso escasamente productivo como es la vivienda.

Los requerimientos de la Unión Monetaria también trascienden a la organización territorial del Estado. Una de las obligaciones a que se someten los miembros de la Unión es a que el Estado garantice el control presupuestario de las entidades regionales y locales. Y de ahí que el legislador central español se haya apresurado a instaurar ese control. Parece claro que la política de saneamiento requiere una reorganización que de una u otra forma también viene exigida por la necesidad de dar una respuesta al problema catalán.

Frente a esta circunstancia, sólo cabe profundizar en las reformas mediante grandes acuerdos (la otra opción, la salida de España de la zona euro, ni parece previsible ni deseable a juzgar por el escaso número de defensores de esa apuesta $)^{18}$.

Así las cosas, parece claro que sería imprescindible un gran reforma constitucional que facilitara la tarea, empezando por los desequilibrios del Estado de las Autonomías. Pero si ese acuerdo no es factible, si debería acentuarse algunas reformas administrativas que puedan contribuir actualmente a la mejora del bienestar y del Estado Social de Derecho. Desde el punto de vista jurídico-administrativo, al que ahora nos ceñimos, cabe hablar:

\section{$1^{\circ}$.- El reforzamiento de la legitimidad democrática de la norma}

Para empezar, no debería restarse importancia a la calidad de los procedimientos, cuando el escaso margen de autonomía se impone a través de normas sobre las que no existe ningún tipo de debate previo. Sí desaparece completamente la ficción del diálogo parlamentario, porque sencillamente se prescinde de él, no puede nadie llamarse a engaño sobre el escepticismo reinante respecto de las instituciones políticas. El uso sistemático del Decreto Ley, que se ha agravado desde la crisis económica, no es de ahora sino un vicio profundo de nuestra Constitución que podía explicarse en el año 1978 por el temor al parlamentarismo y a las estrategias filibusteras, pero que tiene muy poco sentido en un sistema parlamentario tan estable, como el español, que refuerza la mayoría del gobierno mediante el mecanismo del voto de censura constructivo.

Se ha denunciado con frecuencia el abuso del Decreto-Ley ${ }^{19}$, pero se ha observado menos la anomalía de esta institución en un régimen democrático: un procedimiento parlamentario de urgencia en la Cámara y un entendimiento flexible de la reserva de ley son instrumentos que permiten el mismo grado de eficacia sin sacrificar lo que es la esencia del sistema democrático: el debate público, por muy sumario que sea, previo a la adopción de la norma. Que el Decreto Ley no es un instrumento extraordinario para casos de emergencia, sino un medio usual de gobierno, lo prueba el hecho no sólo de su frecuente utilización, sino también su extensión a todos los ámbitos de la acción pública, fundamentalmente el económico, en los periodos de crecimiento y en los de depresión. Solo Italia y Portugal, entre los países de nuestro entorno, poseen este tipo de norma que dice muy poco de la calidad democrática de los procedimientos de creación de derecho. Junto a otros factores como la predominancia de la jerarquía en los partidos políticos, que minimiza el trabajo individual de los diputados, o el sistema de listas cerradas, induce a una percepción de la política en la línea de nuestra tradición autoritaria. La distancia entre gobernantes y gobernados no ha disminuido en estos últimos años sino que probablemente se ha incrementado. Si los procedimientos influyen en la aceptación social de las normas (legitimación a través del procedimiento, en la

17 “Memorando de entendimiento entre la Comisión Europea y España”, de 3 de julio de 2013, BOE, 10-12-12, Punto n³1, Apartado VI.

18 Es curioso que durante la fase aguda de la crisis del euro, las voces más significativas para excluir a algunos países de la moneda europea, provinieran de países como Alemania. Vid. Otte, M.: ¡Frenad el desastre del Euro!, Ariel, Barcelona 2011, cuya tesis es que la salvación del euro se ha hecho a costa de los países débiles y para favorecer los intereses de la banca acreedora de los países económicamente poderosos.

19 Cfr., por ejemplo, Astarloa, I.: “Decretos Leyes” en Alzaga, O.: Comentarios a la Constitución Española de 1978, pág. 143 y ss. Muy significativa ha sido la jurisprudencia constitucional muy complaciente con el uso del decreto-ley al limitarse a aceptar las razones de urgencia aducidas por el Gobierno. Quizá el ejemplo más significativo sea el de la STC 237/2012, sobre el Plan Hidrológico Nacional. 
fórmula de Nicklas Luhman) ${ }^{20}$, difícilmente puede buscarse aceptación en normas que primero se dictan y luego se convalidan en el Parlamento. El Decreto-Ley mina la democracia deliberativa. ${ }^{21}$ Esta grave consecuencia no se sana siquiera cuando el Decreto-Ley es sometido con posterioridad a la tramitación como proyecto de ley, pues la clave de la legitimación democrática, en un régimen de opinión pública, radica en la discusión previa a la aprobación de las normas.

\section{$2^{\circ}$.- La potenciación de la Administración como una organización al servicio del interés general}

Uno de los fenómenos más significativos del Derecho administrativo español, en las más de tres décadas transcurridas bajo la Constitución de 1978, es la creciente dependencia de la organización administrativa de la élite política.

Según el artículo 97 de la Constitución, el Gobierno dirige la Administración, pero desde la Ley 30/1984 de Medidas para la Reforma de la Función Pública, el funcionariado ha perdido peso en la gestión efectiva de la Administración. Ciertamente no se trata de proclamar un gobierno corporativo de la Administración, pero sí de ampliar el ámbito de influencia del funcionariado en las decisiones administrativas. De un lado, disminuyendo la competencia de los órganos cuyos titulares son cargos políticos respecto de aquellos asuntos estrictamente reglados, donde no cabe un margen de apreciación político; de otro, estableciendo mecanismos que garanticen la independencia de la élite funcionarial. El hecho de que después de tanto tiempo, no se haya logrado establecer un modelo de carrera administrativa del funcionariado o disminuir el peso del poder político en la recluta de los altos puestos de la Administración, demuestra patentemente que hay que introducir cambios profundos. No dudamos en que haya que mejorar la trasparencia de la Administración, pero tanto o más importante, es la profesionalización efectiva de la Administración en todos sus ámbitos.

El problema no es de segunda importancia. La creciente debilidad del Estado frente a la sociedad procura también desprotección de los más débiles respecto de los grandes grupos económicos y de interés. La exigencia de un cierto contrapeso público depende tanto de la calidad de la regulación como de la calidad del aparato administrativo que debe promoverla y ejecutarla.

\section{$3^{\circ}$.- La planta de la Administración y del sector público}

Es un hecho que la libertad de formas de la organización pública de la que el legislador se ha servido para alejarse de los controles administrativos e incrementar el clientelismo político, debería tocar a su fin ${ }^{22}$. La planta organizativa de los entes públicos debería reformarse profundamente simplificando su tipología e introduciendo criterios de mercado para la utilización de formas societarias privadas. La Administración cuando actúa como regulador o titular de un poder público debe revestir formas públicas sujetas a las garantías y controles de Derecho Público. La Administración sólo debe emplear formas societarias cuando actúe empresarialmente en el mercado, bien por gestionar servicios públicos, bien por actuar en ciertos sectores estratégicos donde el mercado no es capaz de actuar eficientemente. Esta reforma capital todavía no se ha acometido.

\section{$4^{\circ}$. La mejora de la calidad de las normas}

A) La Ley de Unidad de Mercado: ¿Garantías del mercado único o alteración del régimen constitucional de competencias?

Es curioso que la recepción en la Ley de Economía sostenible de la evaluación de impacto normativo, que pretende una racionalización del ejercicio del poder basada en la justificación de las opciones normativas, no haya venido acompañada de la mejora de la calidad técnica de las normas. Por el contrario, se percibe una enorme improvisación en las reglas nuevas, ayunas, en general, de la reflexión debida. Tampoco en el Informe CORA se detecta este problema, salvo en el aspecto, ciertamente importante, de la codificación del derecho.

La configuración misma del principio de proporcionalidad en el artículo 4.3 de la Ley de Economía Sostenible, como clave de arco de todas las políticas públicas, supone su banalización, ya que dicho principio tiene sentido cuando existe un fin prevalente (la libertad), respecto del cual es posible medir el mayor o menor grado de intervención. Pero no puede aplicarse a todos los ámbitos sin pervertirlo. En esa misma línea la tendencia a absolutizar determinados principios termina por introducir, una amplia confusión. El ejemplo más patente es el de la Ley de Garantía de la Unidad de Mercado, donde se confunde la Unidad de Mercado y el libre establecimiento con la con-

20 Legitimation durch Verfahren, $1^{\mathrm{a}}$ ed. Luchterland, Darmstadt und Neuwied, 1969.

21 Sobre ese concepto, derivado de la teoría de la acción comunicativa, vid. Habermas: Facticidad y Validez: sobre el derecho y el Estado democrático de derecho en términos de teoría del discurso, Trotta, Madrid, 1998. Llama la atención que en la Comisión de Reforma de las Administraciones Públicas (CORA) no se haya acometido este objetivo.

22 Vid. "La urgente reforma del Sector Público", informe elaborado por Esteve Pardo, J., Fernández Farreres, G., Rebollo Puig, M., Tornos Mas, J. y Baño León, J. M.: El Cronista del Estado Social y democrático de Derecho, nº 31, 2012, pág. 26-28. 
sagración irrestricta de un principio distinto: la prevalencia de la libertad de iniciativa económica sobre cualquier otra regla, incluida la de distribución de competencia.

Resulta del tenor literal de esta ley estatal que, aunque exista una ley autonómica que prevea un régimen de autorización para una actividad económica en su territorio, este régimen no se aplicará si dicha actividad cuenta con otra autorización o si en la Comunidad de origen no se exige ningún requisito. Lo cual supone que si ambas Comunidades Autónomas son competentes para regular dicha actividad, y una de ellas no la regula, la eficacia de la desregulación alcanza a todo el territorio del Estado, imponiendo una competencia a la baja en la exigencia de requisitos, pese a que existan razones imperiosas de interés general para hacerlo.

Si una ley autonómica impone para el ejercicio de una actividad o servicio profesional una autorización quienes vivan en ese territorio tienen que obtenerla. Pero si la misma actividad está liberalizada en otra Comunidad, quienes residan en esa Comunidad pueden ejercer en toda España. Más aun interpretando literalmente: si no hay regulación de esa actividad en una Comunidad, quienes residan en ella pueden ejercer en toda España sin requisito alguno. Al margen de la crítica que pudiera hacerse al contenido de la norma, el resultado es que se produce una discriminación donde no la había, ya que en un mismo territorio el régimen jurídico aplicable a un servicio es diferente: no se refuerza la unidad de mercado, sino la competencia por la regulación más flexible, o más, simplemente por la inexistencia de regulación. El principio de igualdad de los ciudadanos en un mismo territorio quiebra y con ello pierde su fundamento la invocación del artículo 149.1.1", cuyo "telos" es justamente conseguir la igualdad en el ejercicio de derechos y deberes constitucionales.

Otra cuestión bien diferente es si bajo la etiqueta de unidad de mercado lo que se busca en realidad es la minimización del control público de las actividades económicas o, más simplemente, la desregulación completa. Pese a que otra cosa proclama la Exposición de Motivos de la Ley, La regulación administrativa de las actividades económicas no es en sí misma un obstáculo a la unidad de mercado.

Manuel Rebollo ${ }^{23}$ ha observado, con razón, que el régimen de la Ley de Unidad de Mercado es diferente al de la Directiva de Servicios, ya que el principio de libre prestación de servicios tiene limitaciones por razones imperiosas de interés general. En la nueva Ley, si una Comunidad Autónoma juzga que una actividad puede estar liberalizada, y otra mediante Ley, juzga que debe estarlo por las razones que la misma Ley estima como admisibles, prevalece la Ley más liberal, en la medida en que cualquier persona que reside en ese territorio va a poder ejercer la actividad sin restricciones, aunque una ley cuya constitucionalidad nadie ha puesto en duda establezca la necesidad de autorización o declaración previa. El resultado no es razonable, porque partiendo de la base de que existen razones de interés general que justifican la autorización o la comunicación previa, es absurdo que se prime a quienes entienden justamente lo contrario. Si las Comunidades ejercen un verdadero poder político, carece de sentido la eficacia supraterritorial de una ley frente a otra.

De otra parte, hay que plantearse si una Ley del Estado es competente para limitar la eficacia territorial de una norma autonómica, pues una cosa es que la autorización concedida en una Comunidad tenga eficacia supraterritorial, y otra bien distinta, que la eficacia territorial de una exigencia de autorización solo afecte a los residentes en ese territorio, y no a quienes hubieran ejercido la actividad en otro.

Por otro lado, es más que discutible que el Estado tenga competencia, en virtud del principio constitucional de unidad de mercado, para limitar la competencia legislativa de las Comunidades Autónomas con base en unos conceptos jurídicos indeterminados ${ }^{24}$. Primero, porque suplanta el monopolio del Tribunal Constitucional para interpretar ese principio, introduciendo por vía subrepticia la armonización de las competencias de las Comunidades Autónomas 25 .

23 “La unidad de mercado y su ordenación” en Cuadernos de Derecho para Ingenieros. Las reformas generales, pág. 42, La Ley, Madrid, 2013. Un análisis muy profundo en línea con lo sostenido en el texto, en Fernández Farreres, G. "Unidad de mercado y libertades de empresa y de circulación en la Ley 20/2013, de 9 de diciembre”, REDA 163 (2014), que he podido manejar durante la corrección de pruebas de este artículo.

24 La idea de que la unidad de mercado no es título atributivo de competencia está muy extendida en la jurisprudencia y en la doctrina. Vid. SSTC 71/1982; 95/84; 14/94; Muñoz Machado, S.: Derecho Público de las Comunidades Autónomas, I, $1^{\text {a }}$ ed., Madrid, 1982, pág. 191; Tena Piazuelo, V.: La Unidad de Mercado en el Estado Autonómico, Escuela Libre Editorial, Madrid, 1997, págs. 283 y ss. Alberti Rovira, E.: Autonomía política y unidad económica (las dimensiones constitucional y europea de la libre circulación y de la unidad de mercado), Civitas, Madrid, 1995. Fernández Farreres, G.: La contribución del Tribunal Constitucional al Estado Autonómico, lustel, Madrid 2005, págs. 411-413. Sostiene lo contrario, De la Quadra-Salcedo Janini: Mercado Nacional único y Constitución, Madrid, 2008. Sobre la base del artículo $149.11^{\mathrm{a}}$ y $13^{\mathrm{a}}$ observa que el Estado tiene atribuida competencia para promover la unidad de mercado (págs. 128-129)

25 Vid la STC 76/1983, F.J.4C: “el legislador ordinario no puede dictar normas meramente interpretativas, cuyo exclusivo objeto sea precisar el único sentido, entre los varios posibles, que debe atribuirse a un determinado concepto o precepto de la Constitución; pues , al reducir las distintas posibilidades o alternativas del texto constitucional a una sola, completa de hecho la obra del poder constituyente que sitúa finalmente en el mismo plano, cruzando al hacerlo la línea divisoria entre el poder constituyente y los poderes constituidos". En similares términos la STC 214/1989 F.J. $5^{\circ}$ que declara la inconstitucionalidad del artículo 5 LRBRL en su redacción originaria. En el caso de la Ley de Unidad 
Segundo, porque permite también, en contra de la jurisprudencia constitucional, limitar la eficacia de las leyes autonómicas. En efecto un acto administrativo dictado de acuerdo con una ley autonómica, que un particular considere que va en contra de los principios de proporcionalidad o necesidad, podrá ser recurrido ante la jurisdicción contencioso-administrativa basándose en la ley estatal y suspendido automáticamente, si la Comisión Nacional de los Mercados y de la Competencia considera que es contraria a la libertad de establecimiento o de circulación. En consecuencia: se dicta un reglamento, o un acto administrativo, en ejercicio de una ley autonómica no impugnada por el Estado, plenamente en vigor; sin embargo, ese acto o esa disposición puede ser suspendida, automáticamente, por el simple hecho de que la CNMC interponga un recurso contencioso-administrativo, si así lo solicita. No parece que sea una conclusión muy conforme con el artículo 161.2 de la Constitución, que solo prevé ese efecto automático de suspensión para las impugnaciones del Gobierno ante el Tribunal Constitucional. Otros privilegios que la propia Ley reconoce al Estado encajan mal con el orden contencioso - administrativo ${ }^{26}$.

Por último al considerar que el Estado es competente para desarrollar la unidad de mercado mediante una ley que también establece principios, quiebra con la igualdad de rango ente la ley estatal y la autonómica. A través de esa norma transversal, unida a la atribución a la CNMC del privilegio de obtener la suspensión automática de las disposiciones contrarias a la ley, se subvierte la eficacia de la ley autonómica, ya que el juez deberá mantener la suspensión del acto o disposición, que es conforme a una ley autonómica vigente, salvo que pudiera seguirse perturbación grave de los intereses generales (artículo 127, quater). De lo cual se sigue: la interpretación que un órgano administrativo estatal hace de un principio, aplicable también al mismo Estado, prima sobre la interpretación que haga la Comunidad Autónoma de ese mismo principio. Lo que, a nuestro juicio, altera claramente el sistema constitucional de competencias.

\section{B) La dependencia política de los organismos independientes}

También suscita serias dudas la Ley 3/2013 de la Comisión Nacional de los Mercados y la Competencia, que ha venido a refundir en un solo organismo la antigua Comisión Nacional de la Competencia y los organismos reguladores en materia energética, de telecomunicaciones, ferroviarias, económico-aeroportuaria y audiovisual.

Más allá de la oportunidad de la refundición, por lo que hace a la fusión de la función de supervisión de la competencia y de la función reguladora, hay una sospecha no infundada de que la verdadera razón de la reforma ha sido el control de la política de nombramiento de los organismos reguladores. Es significativo que la ley no haya establecido un "vacatio" para que los consejeros nombrados por anteriores gobiernos pudieran completar sus mandatos. Por el contrario la constitución de la nueva CNMC, inmediatamente después de la entrada en vigor de la ley (al día siguiente de su publicación en el BOE), es indiciaria del fin último de la norma. La estructuración del organismo en dos salas (de competencia y de supervisión regulatoria), además del régimen de rotación entre Consejeros, acentúa el carácter político de los nombramientos, puesto que no es verosímil que pueda haber expertos en materias tan diferentes como la competencia, las redes eléctricas o las redes ferroviarias. Los nombramientos habidos no han hecho sino confirmar el deseo del legislador de brindar al gobierno un control efectivo del nuevo organismo ${ }^{27}$.

\section{C) La reforma del régimen local mediante la centralización del control en el Estado}

La impresión de que se ha impuesto una verdadera mutación constitucional a través del control del déficit público y de la sostenibilidad de la hacienda, se confirma con la lectura de la Ley 27/2013 de 27 de diciembre, que reforma profundamente el régimen local, mucho más allá del control financiero:

\footnotetext{
de Mercado, la mayoría de sus preceptos carecen de un título competencial que le de soporte, ya que lo que hacen es interpretar el principio de unidad de mercado, y las libertades de libre establecimiento y prestación de servicios, que son derivadas de dicho principio. Difícilmente esas libertades pueden ampararse en la legislación mercantil, ni en las bases de planificación general de la actividad económica, ni en el régimen jurídico de las Administraciones Públicas (salvo los preceptos que son redundantes respecto de lo establecido en la LRJPAC (como consecuencia de la trasposición de la Directiva de Servicios), y mucho menos en el artículo149.1.1 ${ }^{\mathrm{a}}$, no sólo porque supone otorgarle una fuerza expansiva que volatiliza el régimen de distribución de competencias, sino porque algunos de sus preceptos no contribuyen a la igualdad, lo que promueven es una desigualdad basada en la preeminencia de la desregulación.

26 Por ejemplo, la impugnación por la CNMC de cualquier acto o disposición atrae para la Audiencia Nacional la competencia (incluso si hay otro procedimiento pendiente en otro Juzgado o Tribunal), rompiendo con el principio tradicional de que el juez ordinario se determina por la sede la Administración autora del acto impugnado. O la estrafalaria idea de que cualquier particular puede adherirse al recurso como parte recurrente en cualquier fase del recurso planteado por la CNMC, saltando por encima de la firmeza del acto consentido.

27 Cfr., por ejemplo, Garicano, L: El dilema de España. Ser más productiva para vivir mejor, Planeta, 4 a ed. Barcelona, 2014, pág. 116: "Sin ninguna excepción, todos los nombramientos de reguladores y supervisores realizados por el Gobierno actual han sido cargos políticos, amigos del régimen. En definitiva, se ha nombrado a aquellas personas con las que el Gobierno puede contar para que obedezcan sus indicaciones". La observación, que puede estimarse radical, responde a una preocupación muy generalizada. Vid. Sánchez Morón, M.: "Política de Nombramientos", en El Cronista del Estado Social y Democrático en Derecho, n 43 , marzo de 2014, págs. 48-55.
} 
1. La distinción entre municipios de más o menos de 20.000 habitantes es crucial, porque los que se encuentran por debajo de esa cifra ven muy mermadas sus posibilidades de prestación de servicios y se someten a un severo control del Estado y de las Diputaciones Provinciales.

2. La atribución de nuevas funciones a las Diputaciones Provinciales aleja cualquier posibilidad de incrementar la interiorización autonómica del régimen local. Esta Ley 27/2013, en rigor, hace mucho más dependientes a los municipios de la legislación y del control del Estado, de modo que cabe hablar claramente de una neoasunción de competencias, en materia de régimen local, por parte del Estado, a la que ha venido dando pábulo la jurisprudencia constitucional, mediante su interpretación "sui generis" de la materia régimen local.

3. Hay una limitación drástica de la autonomía local, en cuanto al ejercicio discrecional de competencias no reservadas al Estado o a las Comunidades Autónomas. Se liquida la cláusula general de competencia de las entidades locales para todos los municipios. El municipio, tras la nueva ley, sólo puede tener competencias propias en las materias del artículo 25.2 y en la medida en que la ley se las atribuya, ley que debe ir acompañada de una memoria económica, asegurar la eficiencia de los recursos locales y "evaluar las consecuencias de la implantación de servicios locales conforme a los principios de descentralización, eficiencia, estabilidad y sostenibilidad financiera".

Las competencias facultativas, es decir, las que no son propias o delegadas (artículo 7.4), quedan de hecho sometidas a la Administración de tutela (la Administración del Estado, respecto de la tutela financiera en el régimen común, además de la Administración competente por razón de la materia). Es decir, no hay competencias facultativas sin el dictamen favorable de la Administración superior.

Esta reforma, muy profunda en verdad, perfectamente razonable en cuanto se refiere a la limitación competencial de las entidades locales, muy discutible en cuanto a la distinción entre municipios de más y de menos de 20.000 habitantes, adolece, sin embargo, de grandes imprecisiones, cuando no oscuridades, tanto en el régimen transitorio como en preceptos clave ${ }^{28}$. Para muestra un botón: la redacción del artículo 25 no deja claro si el Estado y las Comunidades Autónomas pueden atribuir "competencias propias" a las Corporaciones Locales, fuera de las materias reguladas en el número 2. El inciso "en todo caso" del número 2 citado, que se arrastra de la redacción primitiva de la LRBRL, parece indicar "sensu contrario" que es posible esta atribución, lo que se justificaría, respecto al Estado, por el hecho de que siempre una ley estatal sectorial podría ampliar el elenco de materias. Sin embargo, los apartados 3, 4 y 5 parecen referirse solo a las materias del artículo 25.1. Esta ambigüedad se traslada al régimen transitorio. La ley nada prevé sobre las competencias que los municipios venían ejerciendo al amparo de la legislación anterior, y que ahora no se encuentran en el elenco de materias del artículo 25. Respecto de las que están reconocidas en leyes sectoriales del Estado o de las Comunidades Autónomas, parece lógico que se mantengan. Pero subsisten las dudas sobre las que los municipios desempeñaban sin expresa atribución de una ley, de acuerdo con la cláusula general de competencia del artículo 25 LRBRL, en la redacción anterior a la nueva ley²9.

\section{LA REFORMA SILENCIOSA DEL EQUILIBRIO CONSTITUCIONAL}

Se ha dicho ya que el impacto de la Unión Monetaria sobre la gobernación del Estado es de tal porte que exigiría una reforma constitucional de la organización territorial y una gran coalición en el gobierno. Se aduce, sin embargo, y no sin razón, que no existe el consenso suficiente para acometer una reforma, ni desde el punto de vista territorial, ni desde la perspectiva de alguno de los grandes consensos que articularon la Constitución de 1978. La cuestión es, no obstante, que mientras se pospone cualquier reforma constitucional, la Constitución se está, en no poca medida, inaplicando a ojos vista ${ }^{30}$.

Se ha denunciado el hecho de que, por ejemplo, la STC sobre el Estatuto Catalán se ignora en muchas ocasiones por el legislador catalán. Lo cual es cierto y rechazable. Pero no puede ignorarse, al mismo tiempo, que el legislador estatal, al calor de las reformas que la Unión Europea impone, está también ignorando el régimen de distribución de competencias. Lo hace claramente, a mi juicio, en el caso de la Ley de Garantía de la Unidad de Mercado, por lo que supone de alteración real de la competencia de las Comunidades Autónomas en materia

28 Cfr. dos análisis muy diferentes, aunque referidos a la primera propuesta de reforma, Font i Llovet, T.; Galán Galán, A.: “Racionalización y sostenibilidad de la Administración Local: ¿es esta la reforma?”; Díaz Lema, J. M.: “El Anteproyecto de Ley de racionalización y sostenibilidad de la Administración Local: ¿cambio de rumbo en la Administración Local española?”, ambos en Anuario del Gobierno Local 2012.

29 El Ministerio de Hacienda y Administraciones Públicas se ha visto obligado, ante la avalancha de dudas, a publicar una "Nota explicativa" de 4 de marzo de 2013 (sic) en la que da su interpretación a la ley, explicación que lógicamente sería innecesaria si la ley tuviera la claridad técnica exigible y que, por lo demás, tampoco tiene efecto jurídico alguno, salvo el conocimiento del criterio que sostiene la Administración estatal sobre una ley clave en la organización territorial.

30 Entre muchos testimonios, vid. Muñoz Machado, S.: “La cuarta vía”, El Cronista del Estado Social y democrático de Derecho, n 42. Febrero de 2014 . 
económica. De manera que, en el fondo, se reproduce en la legislación ordinaria las consecuencias de la falta de un acuerdo mínimo sobre los grandes temas.

La falta de acuerdo sólo tiene una excepción: es generalizado el consenso sobre la necesidad de mantener nuestra pertenencia a la Unión Monetaria. Paradójicamente es la Unión Europea, cuyo déficit de legitimación democrática es notorio, la que está permitiendo el mantenimiento de una uniformidad básica en España. A falta de acuerdo entre nosotros, bien está que desde fuera se impulse una política mínimamente coherente. El problema es si la sociedad española soportará sin fractura una situación en la que las reformas no resultan de las opciones electorales mayoritarias, sino de decisiones gubernamentales europeas muy alejadas del debate político-electoral interno. 